\title{
Analisis Konsumsi Bahan Bakar Kapal Niaga Berdasarkan American Society for Testing Materials the Institute of Petroleum (ASTM-IP)
}

\author{
Nafi Almuzani ${ }^{a}$, Bambang Wahyudi ${ }^{\mathrm{b}}$, Imam Fahcruddin ${ }^{\mathrm{c}}$

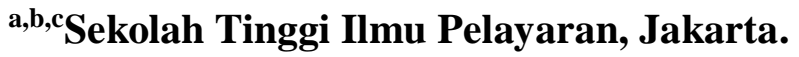 \\ aEmail : nafistip72@gmail.com \\ bEmail: bambangwahyudi23@gmail.com \\ Email: fahrudinuin@gmail.com
}

\begin{abstract}
ABSTRAK
Biaya operasional kapal didominasi oleh pembelian bahan bakar minyak. Lebih lanjut, monitoring konsumsi bahan bakar minyak di kapal kurang di perhatikan, karena officer lebih berkonsentrasi pada bagaimana kapal bisa bergerak sampai ketujuan. Tujuan penelitian ini adalah mengetahui koreksi yang harus dilakukan serta dampak yang ditimbulkan apabila konsumsi bahan bakar minyak yang melalui Flowmeter di kapal dikoreksi menggunakan ASTMIP. Subjek penelitian ini adalah empat kapal pada perusahaan PT. S. I. Ship Management dengan specific grafity (SG) sebesar 0.9601. Dari hasil penelitian menunjukkan output data Flowmeter pada mesin induk harus dikalikan dengan factor for reducting volume to $15^{\circ} \mathrm{C}$ yang ada pada ASTM-IP sehingga berdampak pada keakuratan dalam pelaporan konsumsi bahan bakar. Akibatnya biaya operasional berkurang dan perusahaan kapal dapat menjual jasanya secara bersaing.
\end{abstract}

Kata Kunci: optimalisasi, sistem gas lembam, penanganan muatan, crude oil.

\section{PENDAHULUAN}

Anggaran belanja energi menempati posisi tiga besar dalam daftar belanja bulanan perusahaan pelayaran, sehingga harus di jaga ketat fluktuasinya karena pengaruhnya sangat besar terhadap efisiensi biaya produksi. Dengan perubahan harga bahan baku energi di Indonesia memberikan reaksi yang sangat sensitif bagi pelaku industri. Selain itu, minimnya pemahaman dan penerapan manajemen energi yang baik juga sangat diperlukan untuk efektifitas konsumsi energi.

Salah satu komponen penting penggerak kapal adalah bahan bakar minyak (BBM). Bahan bakar minyak digunakan untuk menggerakkan mesin diesel sehingga menghasilkan daya dorong penggerak kapal. BBM yang dibutuhkan mesin diesel didapat dari supplier minyak dengan membelinya, dimana bahan bakar tersebut dikirim ke kapal di pelabuhan melalui mobil tangki atau dikirim ke kapal saat kapal di laut dengan memakai sarana tongkang. Bahan bakar yang dibeli perusahaan pelayaran merupakan biaya operasional kapal yang berada pada kisaran $70 \%$ dari biaya operasi kapal tersebut. Oleh karena itu, semua perusahaan pelayaran seharusnya selalu mengawasi konsumsi BBM di kapalnya secara ketat dan melekat agar tidak ada pemborosan konsumsi BBM (KP Teknik; 2007).

Dari hasil studi pendahuluan yang dilakukan peneliti selama di kapal, dibagian Armada dan operasi, diperoleh monitoring BBM banyak memiliki kendala. Kendala yang sering dijumpai adalah para pengawas di kantor lebih berkonsentrasi bagaimana kapal dapat beroperasi, tiba ditempat tujuan tepat waktu dan selamat, sedangkan monitoring konsumsi BBM secara detail di kapal tidak dilakukan, khususnya BBM setelah melalui Flowmeter. Hal ini berakibat kapal yang diawasinya tidak efisien dalam konsumsi BBM sehingga kedepannya akan mengganggu keuangan perusahaan dalam mengoperasikan kapal tersebut.

Dalam dunia perkapalan, bahan bakar minyak yang digunakan diantaranya Heavy Fuel Oil (HFO), Medium Fuel Oil (MFO), dan 
Intermediate Fuel Oil (IFO) (MAN B \& W., 2010). MFO merupakan BBM yang bukan termasuk jenis distilate, tetapi termasuk jenis residue yang lebih kental pada suhu kamar serta berwarna hitam pekat. Minyak jenis ini memiliki tingkat kekentalan yang tinggi dibandingkan minyak diesel. Mutu MFO yang baik harus memenuhi batasan sifat - sifat yang tercantum pada spesifikasi dalam segala cuaca. Karena secara umum bahan bakar MFO hanya dapat dipompa dan diatomisasikan setelah melalui pemanasan terlebih dahulu. Pemakaian BBM jenis ini umumnya untuk pembakaran langsung pada industri besar dan digunakan sebagai bahan bakar untuk steam power station serta harganya lebih murah dari pada HFO (Simatupang, 2018).

\section{Untuk membatasi masalah,} diasumsikan perhitungan konsumsi bahan bakar MFO hanya pemakaian di mesin induk saja dan tidak dimasukkan atas kerugian bahan bakar MFO yang dipakai di motor bantu generator dan ketel uap (Taher, 2018). Daya efektif atau Brake Horse Power (BHP) adalah parameter yang menunjukkan kemampuan mesin dalam membangkitkan daya pada berbagai kondisi operasi yang diberikan dengan satuan kW. Konsumsi bahan bakar spesifik atau Spesific Fuel Oil Consumption (SFOC) merupakan parameter unjuk kerja mesin yang berhubungan dengan nilai ekonomis sebuah mesin, karena dengan mengetahui hal ini dapat dihitung jumlah bahan bakar yang di butuhkan untuk menghasilkan sejumlah daya dalam selang waktu tertentu. Konsumsi bahan bakar spesifik (SFOC) dapat di hitung dengan persamaan berikut (Baharuddin, 2016) .

dimana

$$
S F O C=\frac{F O C}{B H P},
$$

$$
\begin{aligned}
& \text { FOC }=\text { Fuel Oil Consumption }(\mathrm{kg} / \mathrm{h}) \\
& \text { SFOC }=\text { Spesific FOC }(\mathrm{kg} / \mathrm{kWh}) \\
& \text { BHP }=\text { Brake Horse Power }(\mathrm{kW})
\end{aligned}
$$

Pada umumnya, nilai BHP untuk kapal tertentu sudah tertera dalam database ship particular masing-masing kapal. Dalam penelitian ini, nilai BHP yang digunakan berdasarkan ship particular tanker vessels di perusahan pelayaran Indonesia. Berdasarkan Specification of a 1100 TEU Container Vessels (Bruegge, 2004), SFOC pada mesin induk kapal untuk mesin terbaru era tahun 2000 keatas yang sudah hemat adalah $0.176 \mathrm{~kg} / \mathrm{kWh}$. Lebih lanjut, nilai SFOC tersebut merupakan nilai pada kondisi maksimal (100\%) daya engine. Dalam kondisi operasional kapal, penggunakan SFOC sebesar 85\% (Bruegge, A., 2004) sehingga Persamaan 1 pada kondisi operasional dapat dinyatakan dengan

$$
\begin{aligned}
F O C_{M F O}=0,85 & \times S F O C \\
& \times B H P .
\end{aligned}
$$

Flowmeter merupakan suatu alat ukur untuk mengetahui jumlah pemakaian bahan bakar minyak pada mesin. Fungsi dari Flowmeter adalah mengukur jumlah volume cairan yang lewat pada alat tersebut sehingga diperoleh jumlah volume cairan yang masuk kedalam suatu wadah/tempat atau mesin. Untuk mempermudah dalam memahami posisi Flowmeter pada sistem bahan bakar minyak, berikut ini disajikan skema terkait hal tersebut.

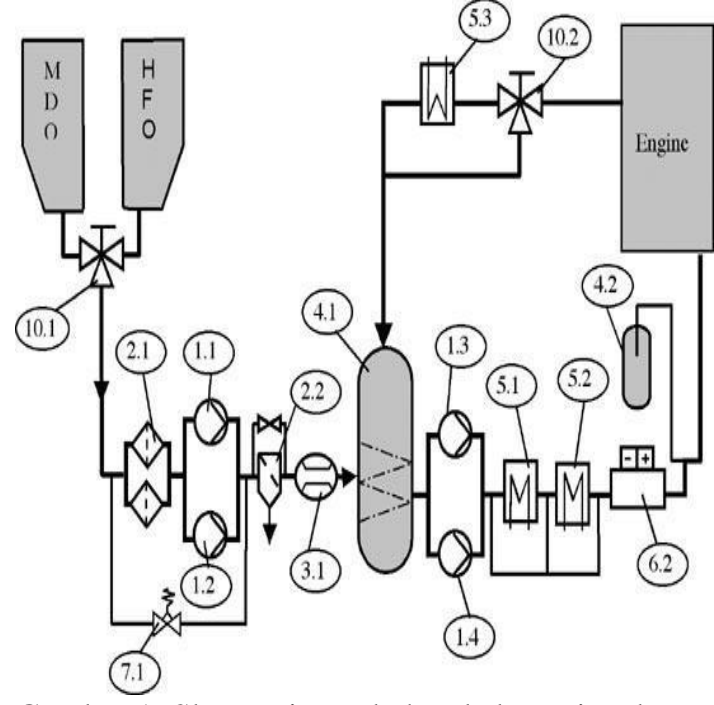

Gambar 1. Skema sistem bahan bakar minyak

Keterangan :

Fuel Supply Booster Module;

Pos. 10.1 Change over valve

Pos. 2.1 Duplex filter

Pos. 1.1, 1.2 Supply pumps 
Pos. 7.1 Pressure control system

Pos. 2.2 Automatic fine filter

Pos. 3.1 Flowmeter measuring system

Pos. 4.1 Mixing + accessories

Pos. 1.3, 1.4 Booster pumps

Pos. 5.1, 5.2 HFO pre-heaters

Pos. 6.2 Viscometer sensor

Pos. 4.2 Dumping tank

Pos. 5.3 MDO cooling unit

Pos. 10.2 MDO change over valve

\section{METODE}

Pada Gambar 1 mengindikasikan bahwa koreksi bahan bakar tidak hanya dilakukan pada saat sounding di tangki, tetapi yang lebih penting lagi adalah koreksi yang harus dilakukan setelah bahan bakar melalui Flowmeter, mengingat temperatur dan densitas bahan bakar di tangki awal berbeda dengan temperatur dan densitas bahan bakar setelah melalui Flowmeter. Agar hasil penelitian ini akurat, maka konsumsi bahan bakar MFO yang akan dikoreksi densitas dan temperaturnya merupakan bahan bakar setelah melalui Flowmeter. Jadi untuk menghitung konsumsi bahan bakar MFO tidak perlu menghitung secara manual, cukup dengan melihat Flowmeter kemudian melakukan koreksi hasil Flowmeter dengan menggunakan tabel ASTM-IP (American Society for Testing Materials the Institute of Petroleum).

Mengingat material bumi, terutama bahan cair sangat rentan berubah dengan kondisi suhu atau temperatur maka koreksi standar perhitungan konsumsi BBM harus dilakukan kemudian distandarkan seluruh dunia. Temperatur yang dijadikan acuan untuk standarisasi adalah $15^{\circ} \mathrm{C}$, jadi dimanapun lokasi dalam melakukan perhitungan konsumsi BBM, agar tidak merugikan pihak lain maka perhitungan yang dilakukan harus dikonversi ke temperatur $15^{\circ} \mathrm{C}$.

Tabel standar ukur yang digunakan untuk melakukan koreksi densitas dan temperatur pada BBM di kapal adalah tabel ASTM-IP. Didalam tabel tersebut terdapat nilai koreksi volume yang digunakan untuk mengkonversi muatan minyak apabila terjadi perbedaan temperatur dan densitas BBM yang ada dalam kapal. Tujuan penelitian ini adalah mengetahui koreksi yang harus dilakukan serta dampak yang ditimbulkan apabila konsumsi bahan bakar minyak yang melalui Flowmeter di kapal dikoreksi menggunakan tabel ASTM-IP.

Jenis penelitian yang digunakan adalah analisis deskriptif kuantitatif. Subjek penelitian adalah beberapa kapal PT. S. I. SHIP MANAGEMENT yang mana crew dalam kapal tersebut tidak melakukan koreksi pada saat pelaporan konsumsi bahan bakar minyak. Proses tahapan dalam penelitian ini disajikan dalam diagram berikut.

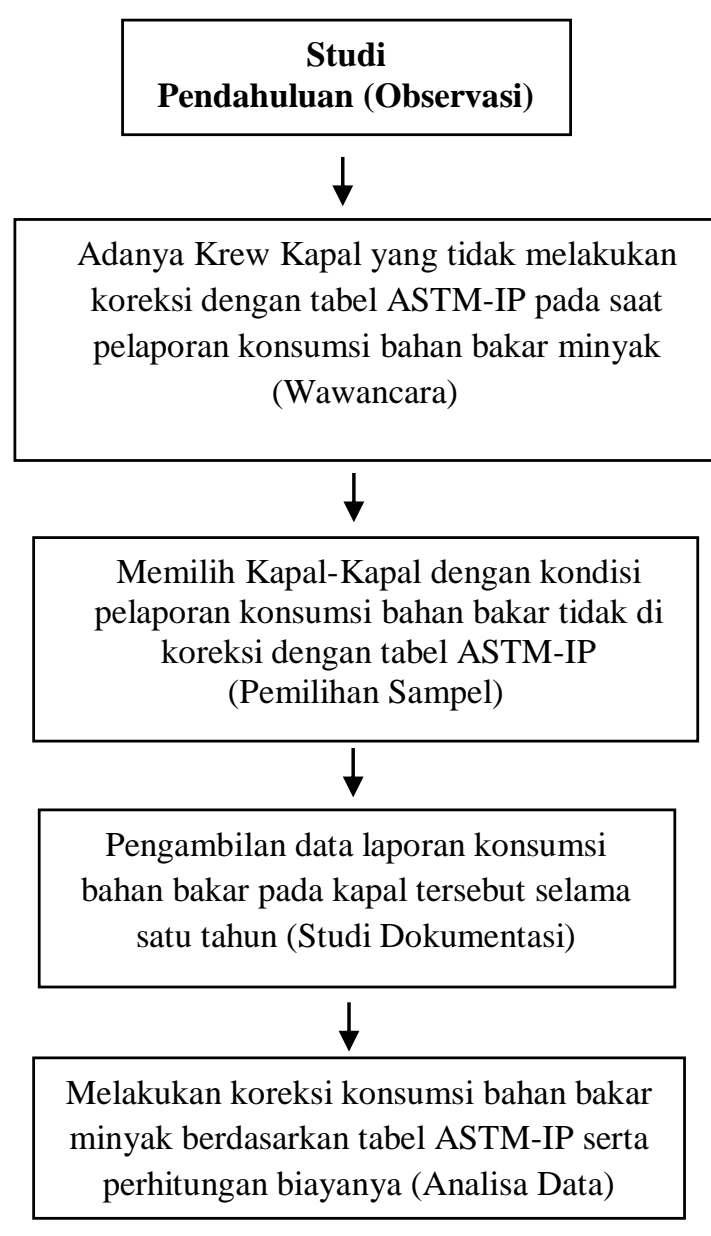

Gambar 2. Tahap-tahap penelitian

\section{HASIL DAN PEMBAHASAN}

Berdasarkan tahapan pemilihan subjek penelitian, diperoleh empat kapal yang terindikasi tidak melakukan koreksi temperatur dan densitas pada saat pelaporan konsumsi bahan bakar, yaitu: 
Tabel 1. Subjek Penelitian

\begin{tabular}{|c|l|l|l|}
\hline NO & NAMA KAPAL & GRT & TIPE MESIN \\
\hline 1 & MV. SIKUD & 7.717 & $\begin{array}{l}\text { MAKITA- } \\
\text { MITSUI MAN } \\
\text { B\&W 3939 KW }\end{array}$ \\
\hline 2 & MT. SIMAS & 13.960 & $\begin{array}{l}\text { YICHANG MAN } \\
\text { B\&W 4900 KW }\end{array}$ \\
\hline 3 & MT. SITO & 1.942 & $\begin{array}{l}\text { AKASAKA 2059 } \\
\text { KW }\end{array}$ \\
\hline 4 & MV. SIKUT & 33.348 & $\begin{array}{l}\text { STX MAN 9480 } \\
\text { KW }\end{array}$ \\
\hline
\end{tabular}

Peneliti melakukan koreksi temperatur dan densitas dalam perhitungan konsumsi bahan bakar empat kapal tersebut, kemudian membandingkan dengan laporan awal, serta menghitung penghematan biaya pembelian bahan bakar MFO. Lebih lanjut, peneliti membuat grafik konsumsi bahan bakar sebelum dan sesudah dikoreksi untuk memudahkan dalam mendeskripsikan hasil perhitungan konsumsi bahan bakar. Selanjutnya dibuat diagram batang biaya pembelian bahan bakar MFO sebelum dan sesudah dikoreksi tabel ASTM-IP, sehingga terlihat seberapa besar selisih diantara kedua biaya tersebut.

Tabel 2. Laporan Konsumsi Bahan Bakar MFO kapal MV. SIKUD sebelum dikoreksi

\begin{tabular}{|c|c|c|c|c|c|}
\hline \multirow{3}{*}{ No } & \multirow{3}{*}{$\begin{array}{l}\text { Ves } \\
\text { sel }\end{array}$} & \multirow{3}{*}{ Month } & \multicolumn{2}{|c|}{$\begin{array}{l}\text { Running Time } \\
\text { of MFO Usage }\end{array}$} & \multirow{3}{*}{\begin{tabular}{|c} 
MFO \\
Consumpt \\
Actual \\
Consumptio \\
n M/E) \\
(MT/month)
\end{tabular}} \\
\hline & & & \multicolumn{2}{|c|}{$\begin{array}{l}\text { Consumpted } \\
\text { by M/E }\end{array}$} & \\
\hline & & & hrs & $\begin{array}{l}\text { total } \\
\text { days }\end{array}$ & \\
\hline \multirow{12}{*}{1} & \multirow{12}{*}{$\begin{array}{c}\text { MV. } \\
\text { SIKU } \\
\text { D }\end{array}$} & Jan & 315,70 & 13,15 & 158,61 \\
\hline & & Feb & 65,00 & 2,71 & 33,99 \\
\hline & & Mar & 304,40 & 12,68 & 157,46 \\
\hline & & Apr & 326,40 & 13,60 & 166,56 \\
\hline & & May & 159,50 & 6,65 & 73,81 \\
\hline & & June & 209,80 & 8,74 & 94,43 \\
\hline & & July & 195,00 & 8,13 & 98,40 \\
\hline & & Aug & 53,20 & 2,22 & 28,90 \\
\hline & & Sept & 180,40 & 7,52 & 46,57 \\
\hline & & Oct & 208,10 & 8,68 & 113,60 \\
\hline & & Nov & 93,00 & 3,88 & 79,11 \\
\hline & & Dec & 100,00 & 4,17 & 79,03 \\
\hline & & & 2210,50 & 92,10 & 1130,47 \\
\hline
\end{tabular}

Tabel 3. Konsumsi MFO pada kapal MV. SIKUD sebelum dan sesudah dikoreksi

\begin{tabular}{|c|c|c|c|c|c|}
\hline \multirow{3}{*}{ No } & \multirow{3}{*}{$\begin{array}{c}\text { Vess } \\
\text { el }\end{array}$} & \multirow{3}{*}{$\begin{array}{c}\text { Mon } \\
\text { th }\end{array}$} & \multicolumn{2}{|c|}{$\begin{array}{l}\text { MFO Consumpt } \\
\text { (MT/month) }\end{array}$} & \multirow{3}{*}{$\begin{array}{c}\text { Differe } \\
\text { nce } \\
\text { consu } \\
\text { mption } \\
(\mathbf{A}-\mathbf{B})\end{array}$} \\
\hline & & & \multicolumn{2}{|c|}{$\begin{array}{c}\text { Actual Consumption } \\
\mathrm{M} / \mathrm{E} \\
\end{array}$} & \\
\hline & & & $\begin{array}{c}N O \\
\text { COREECTION } \\
\text { (A) } \\
\end{array}$ & $\begin{array}{c}\text { WITH } \\
\text { CORRECTION } \\
(B) \\
\end{array}$ & \\
\hline \multirow{13}{*}{1} & \multirow{13}{*}{$\begin{array}{l}\text { MV. } \\
\text { SIK } \\
\text { UD }\end{array}$} & Jan & 158,61 & 150,70 & 7,91 \\
\hline & & Feb & 33,99 & 32,29 & 1,70 \\
\hline & & Mar & 157,46 & 149,60 & 7,86 \\
\hline & & Apr & 166,56 & 158,25 & 8,31 \\
\hline & & May & 73,81 & 70,13 & 3,68 \\
\hline & & June & 94,43 & 89,72 & 4,71 \\
\hline & & July & 98,4 & 93,49 & 4,91 \\
\hline & & Aug & 28,9 & 27,46 & 1,44 \\
\hline & & Sept & 46,57 & 44,25 & 2,32 \\
\hline & & Oct & 113,6 & 107,93 & 5,67 \\
\hline & & Nov & 79,11 & 75,16 & 3,95 \\
\hline & & Dec & 79,03 & 75,09 & 3,94 \\
\hline & & $\begin{array}{c}\text { TOT } \\
\text { AL }\end{array}$ & $1.130,47$ & $1.074,06$ & 56,41 \\
\hline
\end{tabular}

Sebelum melakukan perhitungan konsumsi bahan bakar yang akan dikoreksi densitas dan temperaturnya, terlebih dahulu disajikan data laporan konsumsi bahan bakar kapal MV. SIKUD selama satu tahun.

Diketahui bahan bakar MFO kapal MV. SIKUD memiliki viskositas $180 \mathrm{cSt}$ dengan specific grafity 0,9601 distandarkan ke densitas $15^{\circ} \mathrm{C}$, dari Tabel 21 (ASTM-IP, 1965) diperoleh 0,9594. Kemudian MFO dipanaskan sampai temperatur $90^{\circ} \mathrm{C}$ dengan nilai standar densitas $15^{\circ} \mathrm{C}$ sebesar 0,9594 diperoleh factor for reducting volume ke $15^{\circ} \mathrm{C}$ dari Tabel 54 (ASTM-IP, 1965) sebesar 0,9501 . Data konsumsi bahan bahan yang melalui Flowmeter pada bulan januari sebesar 2086,38 MT. Jadi konsumsi bahan bakar MFO yang sudah di koreksi dengan ASTM-IP bulan januari sebesar $0,9501 \times 158,61 \approx 150,70 \mathrm{MT}$.

Dengan menggunakan langkahlangkah yang sama seperti perhitungan konsumsi MFO pada bulan Januari, diperoleh tabel perbandingan konsumsi MFO sebelum dan sesudah dikoreksi dengan tabel ASTM-IP dalam setahun. Berikut ini disajikan grafik konsumsi 
MFO kapal MV. SIKUD sebelum dan sesudah dikoreksi dengan tabel ASTMIP.

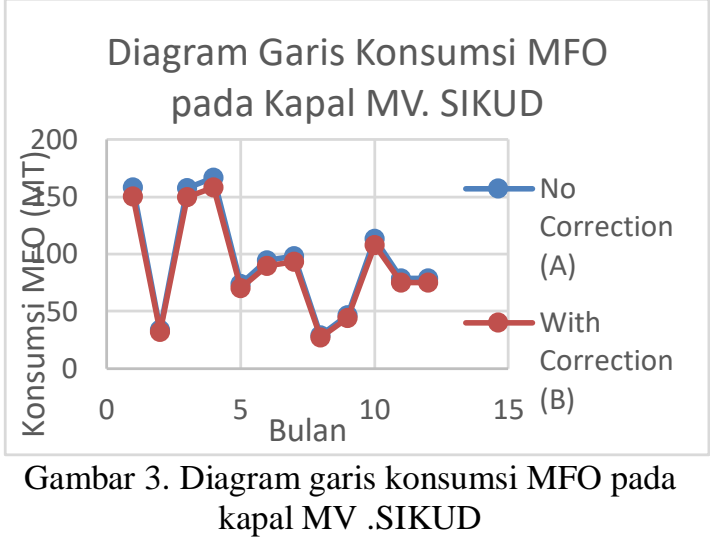

Dari Gambar 3 terlihat bahwa konsumsi MFO pada kapal MV. SIKUD setelah dikoreksi dengan tabel ASTM-IP selalu lebih kecil dari pada konsumsi MFO sebelum dikoreksi tabel ASTM-IP. Hal inilah yang menyebabkan perbedaan laporan sisa bahan bakar kapal dengan pengecekan langsung di atas kapal yang mana selisihnya cukup banyak (over). Lebih lanjut, dengan kondisi seperti inilah, yaitu pengkoreksian konsumsi bahan bakar MFO menyebabkan efisiensi penggunaan bahan bakar.

Diketahui harga bahan bakar MFO berdasarkan acuan harga PT. Ocean Petro Energy periode 1 - 15 Februari 2017, adalah Rp.8.800/Liter (termasuk PPN $10 \%$ dan PPH 0.3\%) dan belum termasuk biaya angkut ke kapal. Untuk hitungan harga MFO per MT sebagai berikut $(8.800:$ SG) x $1000=$ Rp. 9.165.000/MT, belum termasuk biaya transport. Apabila biaya transport Rp. 335/Kg, maka harga bahan bakar minyak MFO Rp. 9.500.000,-/MT.

Berikut ini disajikan diagram batang biaya pembelian bahan bakar MFO pada kapal MV. SIKUD sebelum dan sesudah dikoreksi tabel ASTM-IP.
Diagram batang Pembelian MFO pada Kapal MV. SIKUD

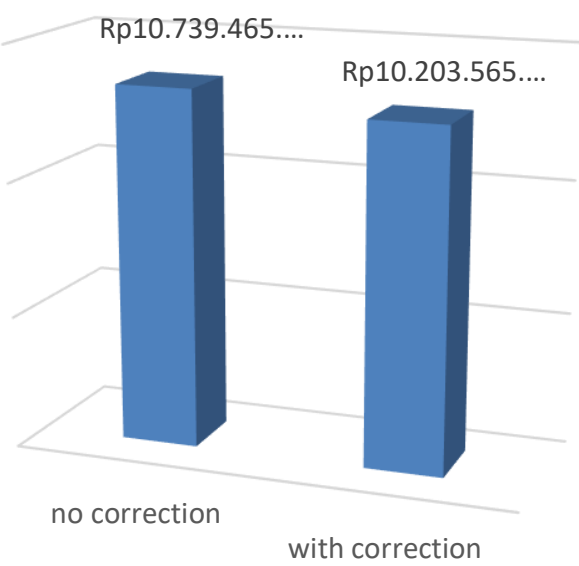

Gambar 4. Diagram batang biaya pembelian bahan bakar MFO pada kapal MV. SIKUD

Dari Gambar 4 terlihat bahwa ketika pelaporan konsumsi bahan bakar MFO sudah dikoreksi dengan tabel ASTM-IP, maka perusahaan PT. S. I. SHIP MANAGEMENT dapat melakukan penghematan biaya pembelian bahan bakar MFO untuk setahun, disajikan dalam tabel berikut ini.

Tabel 4. Penghematan yang bisa dilakukan dalam pembelian MFO pada MV.SIKUD

\begin{tabular}{|c|c|c|c|}
\hline \multicolumn{2}{|c|}{} & \multicolumn{2}{|c|}{$\begin{array}{c}\text { Biaya Pembelian MFO (/year) } \\
\text { (Rp) }\end{array}$} \\
\hline $\begin{array}{c}\text { No } \\
\text { correction }\end{array}$ & $\begin{array}{c}\text { With } \\
\text { correction }\end{array}$ & $\begin{array}{c}\text { No } \\
\text { correction }\end{array}$ & $\begin{array}{c}\text { With } \\
\text { correction }\end{array}$ \\
\hline $1.130,47$ & $1.074,06$ & 10.739 .465 .000 & 10.203 .565 .697 \\
\hline
\end{tabular}

Dengan menggunakan perhitungan yang sama dengan MV. SIKUD, diperoleh tabel penghematan biaya pembelian bahan bakar MFO yang dapat dilakukan PT. S. I. Ship Management.

Tabel 5. Penghematan yang bisa dilakukan dalam pembelian MFO pada MT.SIMAS

\begin{tabular}{|c|c|c|c|}
\hline \multicolumn{2}{|c|}{ FOC $_{M F O}$ (MT/year) } & $\begin{array}{c}\text { Biaya Pembelian MFO (/year) } \\
\text { (Rp) }\end{array}$ \\
\hline $\begin{array}{c}\text { No } \\
\text { correction }\end{array}$ & $\begin{array}{c}\text { With } \\
\text { correction }\end{array}$ & No correction & $\begin{array}{c}\text { With } \\
\text { correction }\end{array}$ \\
\hline $1.734,56$ & $1.648,01$ & 16.478 .358 .000 & 15.656 .087 .935 \\
\hline
\end{tabular}


Tabel 6. Penghematan yang bisa dilakukan dalam pembelian MFO pada MT.SITO

\begin{tabular}{|c|c|c|c|}
\hline \multicolumn{2}{|c|}{} & \multicolumn{2}{|c|}{$\begin{array}{c}\text { Biaya Pembelian MFO } \\
\text { (/year) } \\
\text { (Rp) }\end{array}$} \\
\hline $\begin{array}{c}\text { No } \\
\text { correction }\end{array}$ & $\begin{array}{c}\text { With } \\
\text { correction }\end{array}$ & No correction & $\begin{array}{c}\text { With } \\
\text { correction }\end{array}$ \\
\hline 777,33 & 738,54 & 7.384 .616 .000 & 7.016 .123 .661 \\
\hline
\end{tabular}

Tabel 7. Penghematan yang bisa dilakukan dalam pembelian MFO pada MV.SIKUT

\begin{tabular}{|c|c|c|c|}
\hline \multicolumn{2}{|c|}{ FOC $_{M F O}$ (MT/year) } & $\begin{array}{c}\text { Biaya Pembelian MFO (/year) } \\
(\mathrm{Rp})\end{array}$ \\
\hline $\begin{array}{c}\text { No } \\
\text { correction }\end{array}$ & $\begin{array}{c}\text { With } \\
\text { correction }\end{array}$ & No correction & $\begin{array}{c}\text { With } \\
\text { correction }\end{array}$ \\
\hline 777,33 & 738,54 & 33.152 .891 .000 & 31.498 .561 .739 \\
\hline
\end{tabular}

Umumnya, laporan crew kapal terkait konsumsi bahan bakar MFO adalah $F O C_{M F O}$ sebelum di koreksi, artinya $F O C_{M F O}$ yang dilaporkan hanya berdasarkan output Flowmeter saja, tidak di koreksi dengan tabel ASTM - IP. Lebih lanjut, pihak offiicer juga tidak melakukan koreksi dengan tabel ASTM IP sehingga kerugian yang dialami perusahaan pelayaran sangat besar.

Kerugian pemakaian bahan bakar MFO untuk mesin induk berdasarkan Flowmeter terjadi, karena pada umumnya pengawas di kantor dan pihak kapal tidak melakukan koreksi bahan bakar dengan temperatur dan densitas sesuai dengan tabel ASTM-IP. Artinya, bahan bakar yang dikonsumsi oleh mesin yang melewati Flowmeter seharusnya dikoreksi volume yang tercatat di Flowmeter berdasarkan temperatur dan densitas yang sudah terstandarkan dengan menggunakan tabel ASTM - IP.

\section{SIMPULAN}

Koreksi temperatur dan densitas pada bahan bakar kapal yang melalui Flowmeter harus dilakukan untuk memastikan keakuratan konsumsi bahan bakar, yaitu dengan cara mengkalikan data output Flowmeter dengan factor for reducting volume ke $15^{\circ} \mathrm{C}$ yang didapat dalam tabel ASTM - IP.
Dengan melakukan koreksi pada pelaporan perhitungan konsumsi bahan bakar kapal dapat mengurangi biaya pengeluaran untuk membeli bahan bakar.

\section{DAFTAR PUSTAKA}

ASTM-IP. (1965). American Society for Testing Material the Institute of Petroleum Tables. The Institute of Petroleum, hal. 29 dan 54

Bruegge, A. (2004). Specification of a 1100 TEU Container Vessels. Hamburg: VEGA REEDERI GMBH \& CO KG, hal. 94

Baharuddin. (2016). Perancangan Simulasi Kontrol Otomatis Distribusi Bahan Bakar Tangki Harian pada KM. Madani Nusantara, Jurnal Riset dan Teknologi Kelautan (JRTK): Volume 14, Nomor 1, hal. 61-76.

KP. Teknik. (2007). Proposal untuk penggantian bahan bakar dari $M D O$ ke MFO. Tidak dipublikasikan, hal. 25

MAN B \& W. (2010). MAN B \& W DIESEL-K90ME9-TII Project Guide - Electronically Controlled TwoStroke Engines. Denmark: M. Diesel and Turbo, hal. 2 (7.04)

Simatupang, D. (2018). Optimalisasi Alat Pengabut Bahan bakar Pada Generator Untuk Kelancaran Pengoperasian MV. EGS. CREST. Meteor STIP Marunda, 11(2), 6-15.

Taher, M. U. (2018). Optimalisasi Pengoperasian Boiler Dalam Memproduksi Uap Untuk Menunjang Pengoperasian Kapal MV. SINAR KUTAI. Meteor STIP Marunda, 11(2),16-2 